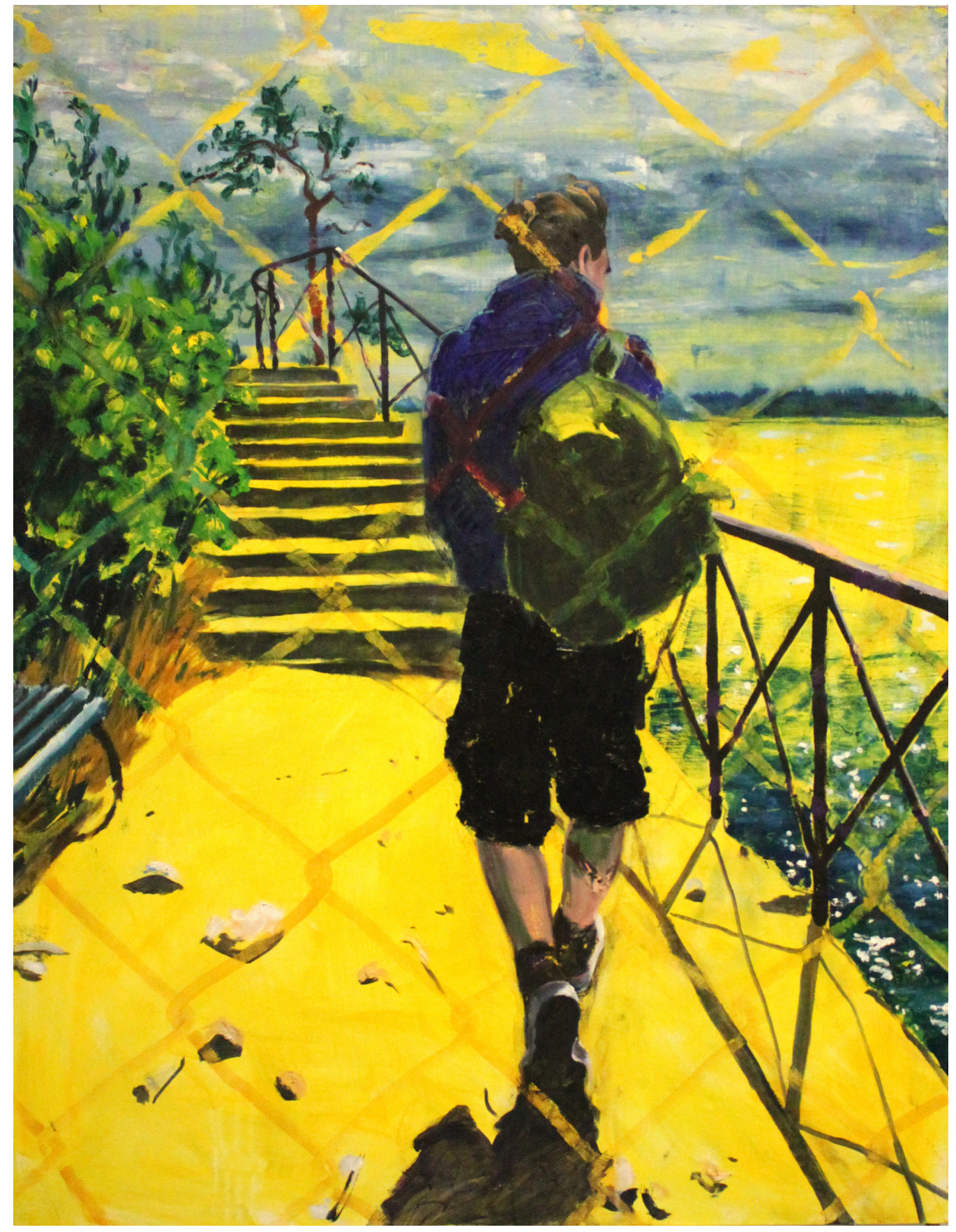

MAARIA JOKIMIES: KESÄ VALUU SORMIEN LÄVITSE (KELTAINEN) (2020) ÖLJY, ÖLJYPASTELLI JA AKRYYLI KANKAALLE ALUMIINIKOMPOSIITTILEVYLLÄ $130 \times 100 \mathrm{CM}$ 


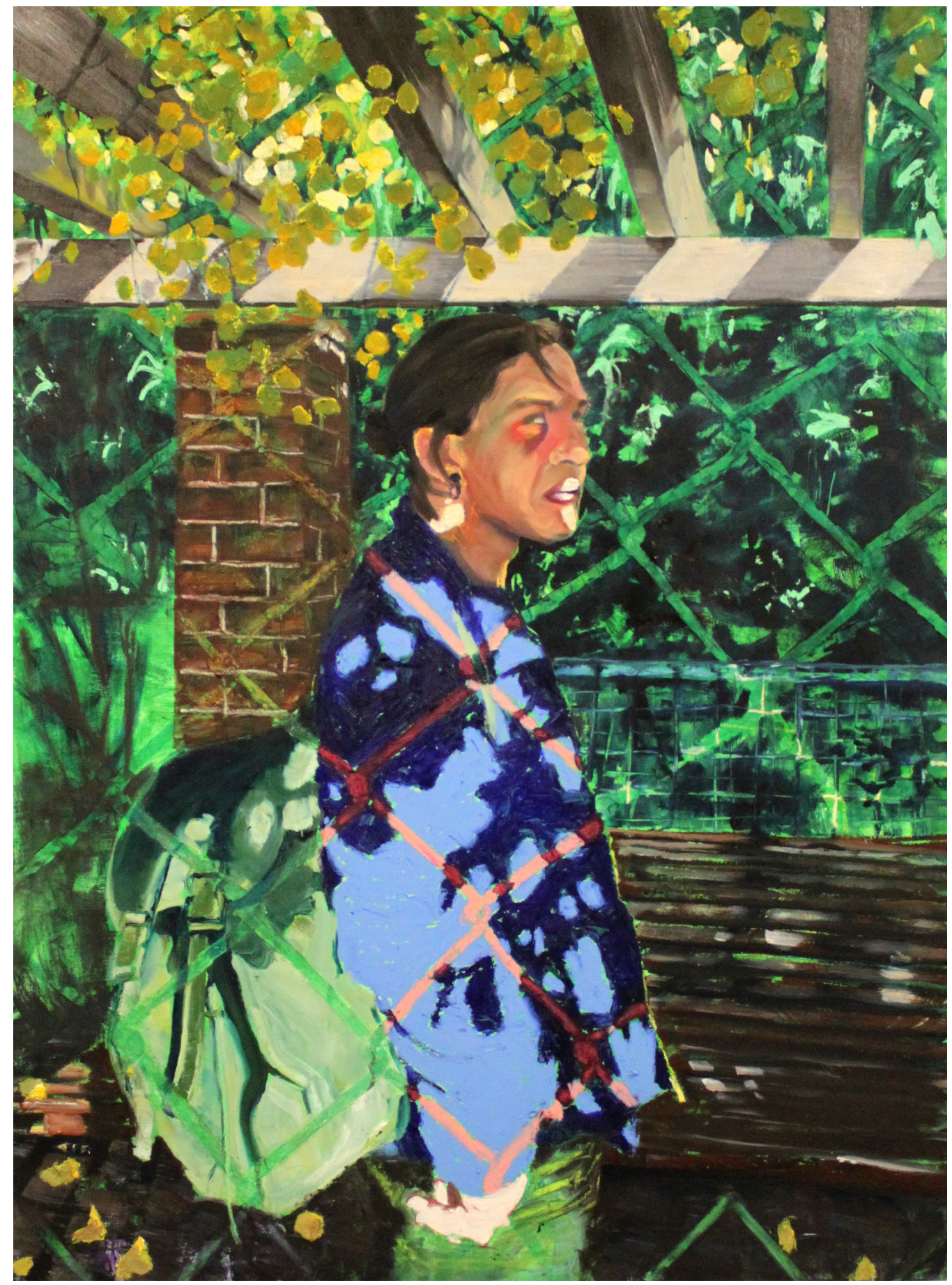

MAARIA JOKIMIES: KESÄ VALUU SORMIEN LÄVITSE (VIHREÄ) (2020) ÖLJY, ÖLJYPASTELLI JA AKRYYLI KANKAALLE ALUMIINIKOMPOSIITTILEVYLLÄ 150 X $110 \mathrm{CM}$. 


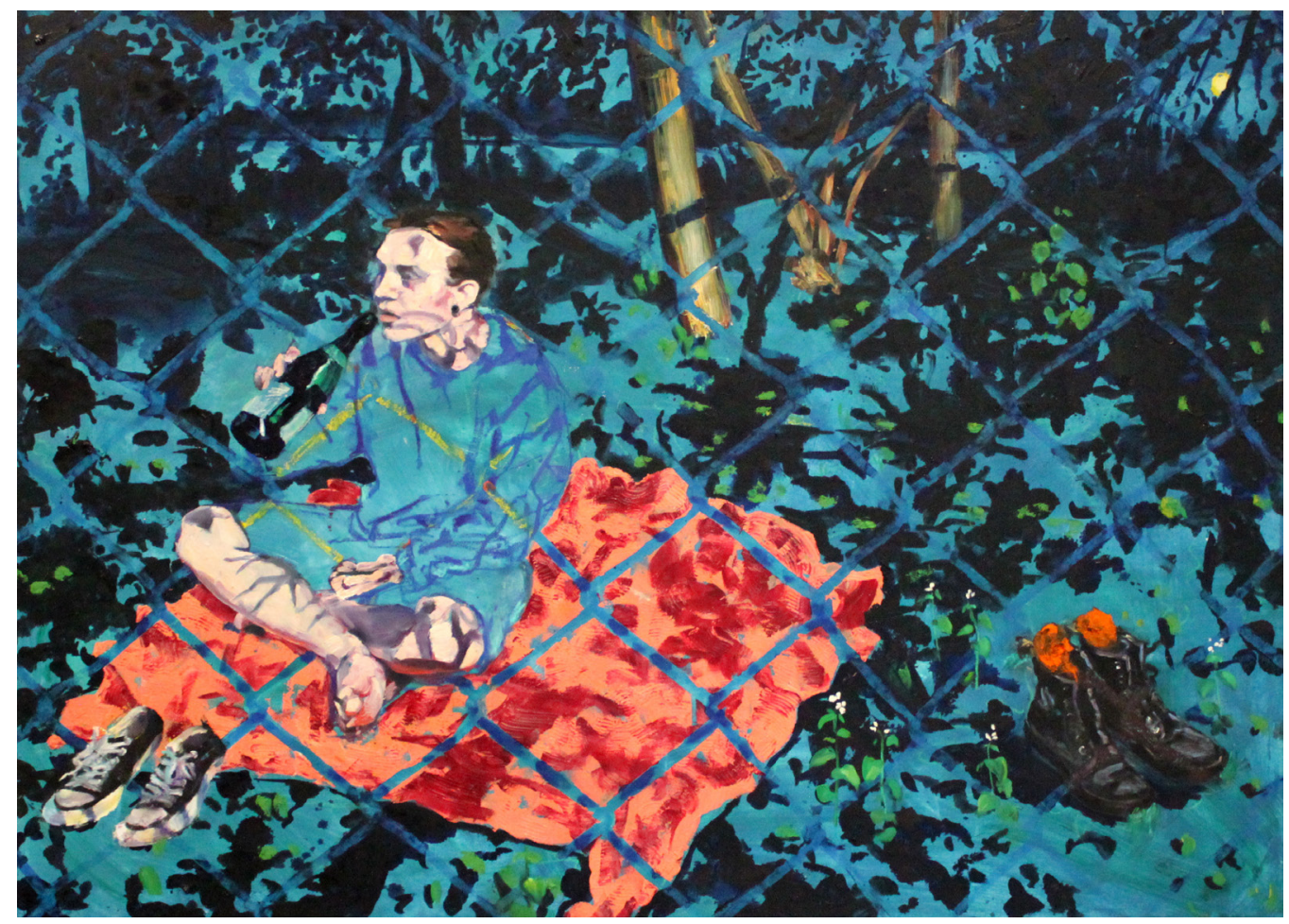

MAARIA JOKIMIES: KESÄ VALUU SORMIEN LÄVITSE (SININEN) (2020) ÖLJY, ÖLJYPASTELLI JA AKRYYLI KANKAALLE ALUMIINIKOMPOSIITTILEVYLLÄ 175 X 130 CM 


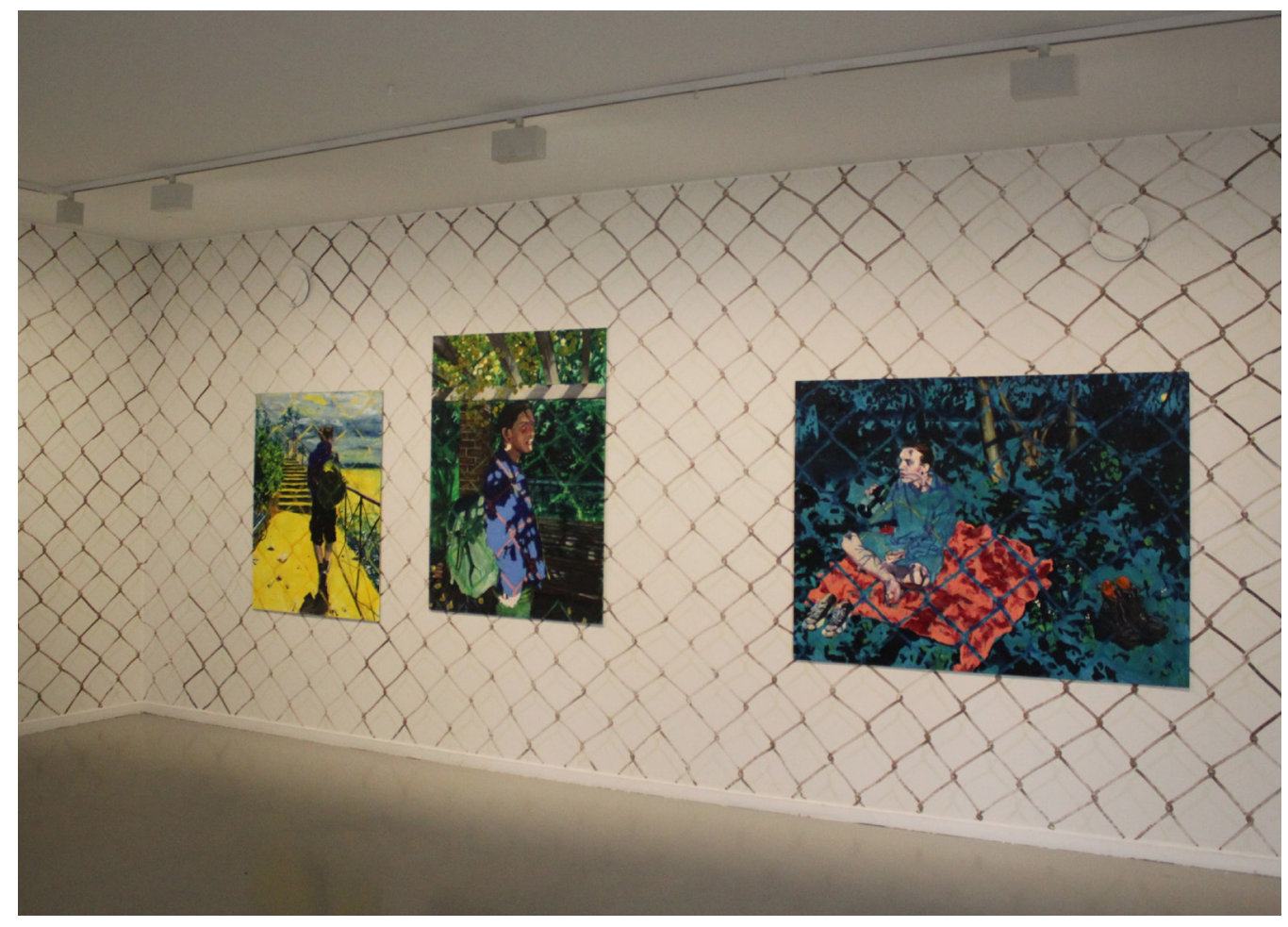

KUVAN KEVÄT 2020 PROJECT ROOM VALOKUVAT MAARIA JOKIMIES 


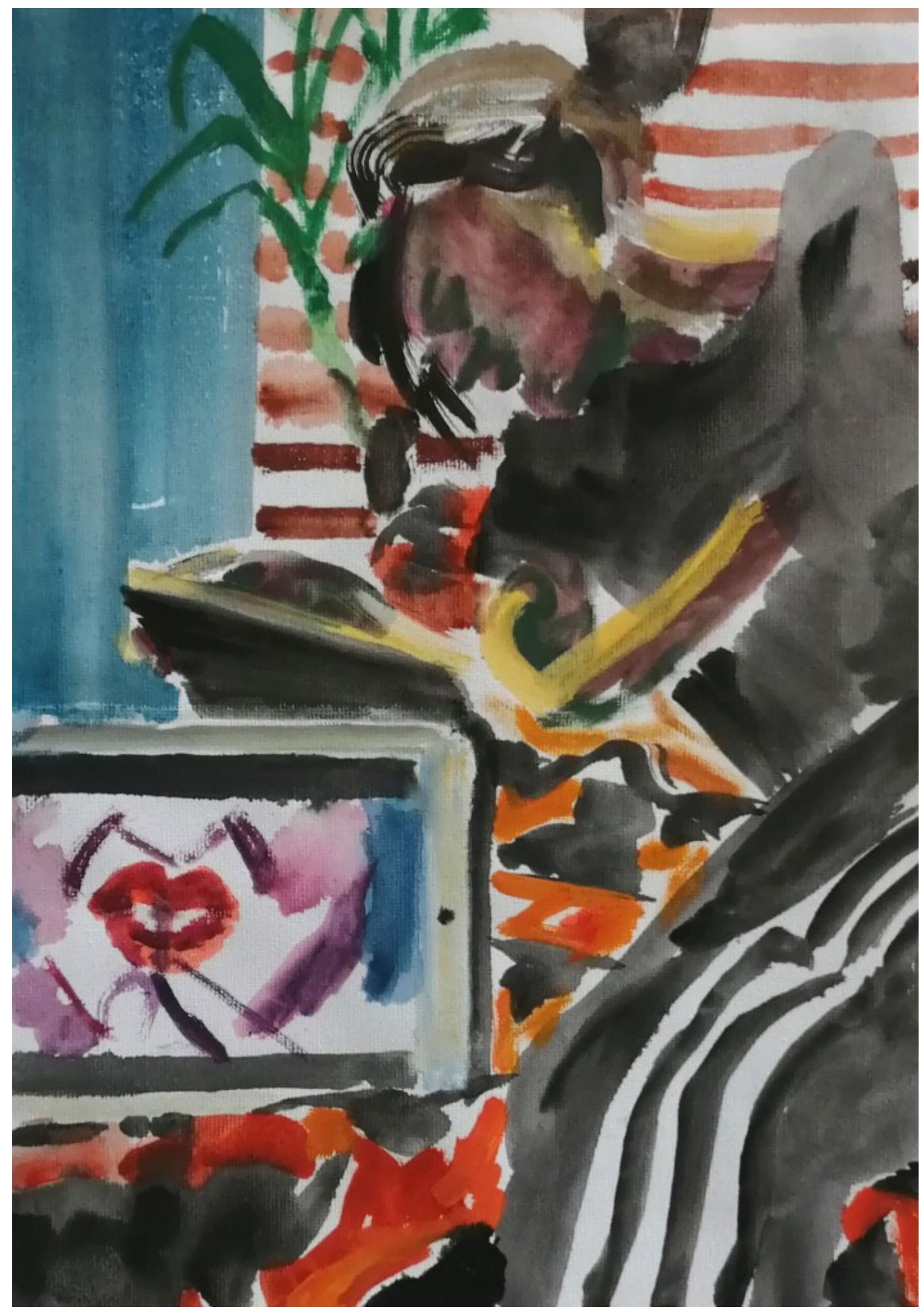

MAARIA JOKIMIES: HÄN LUKEE, KUN KATSON TOSI-TV:TÄ (2O19) VESIVÄRI PAPERILLE $30 \times 21 \mathrm{CM}$ 


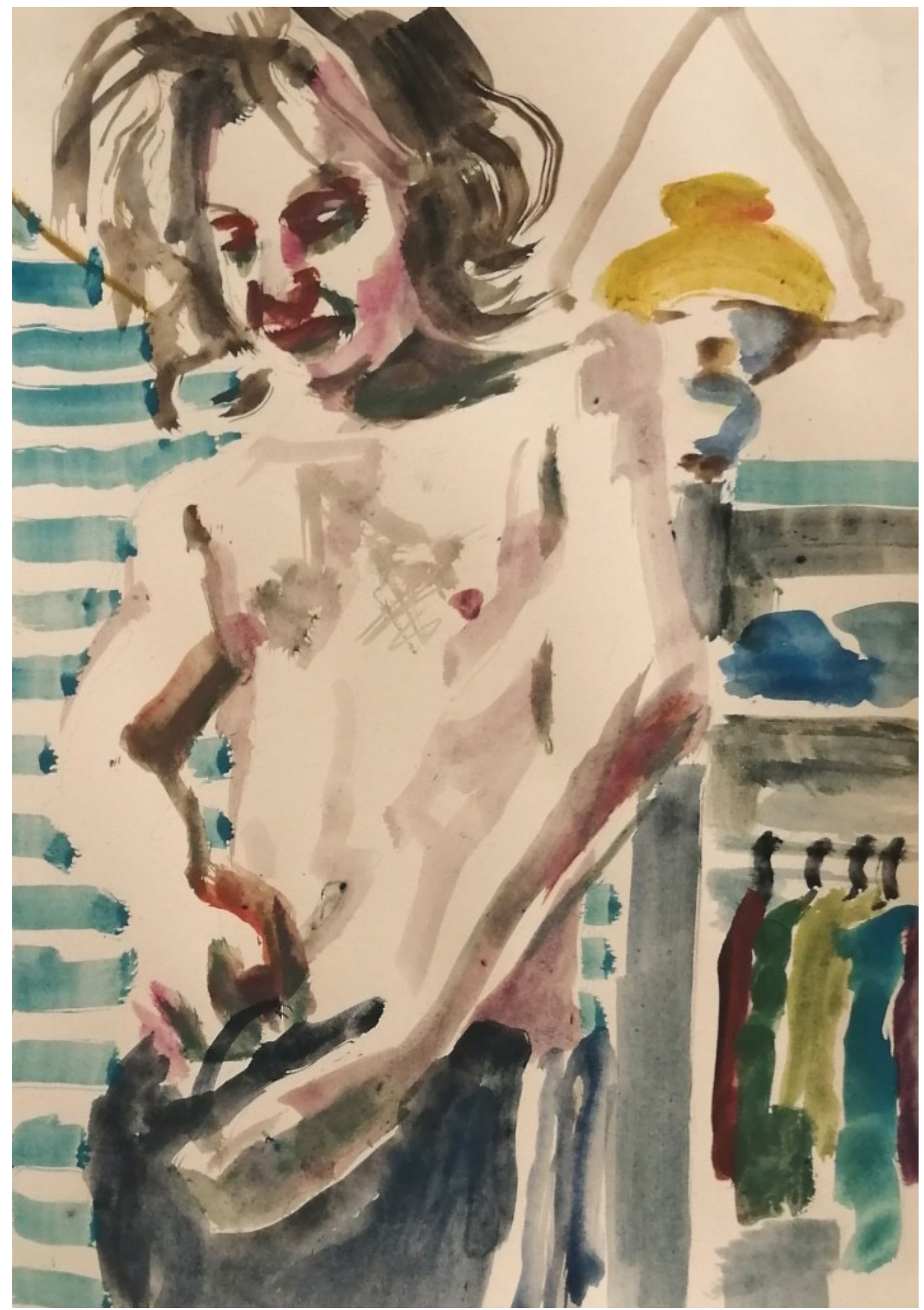

MAARIA JOKIMIES: VERKKARIT (2019) VESIVÄRI PAPERILLE $34 \times 24$ CM 


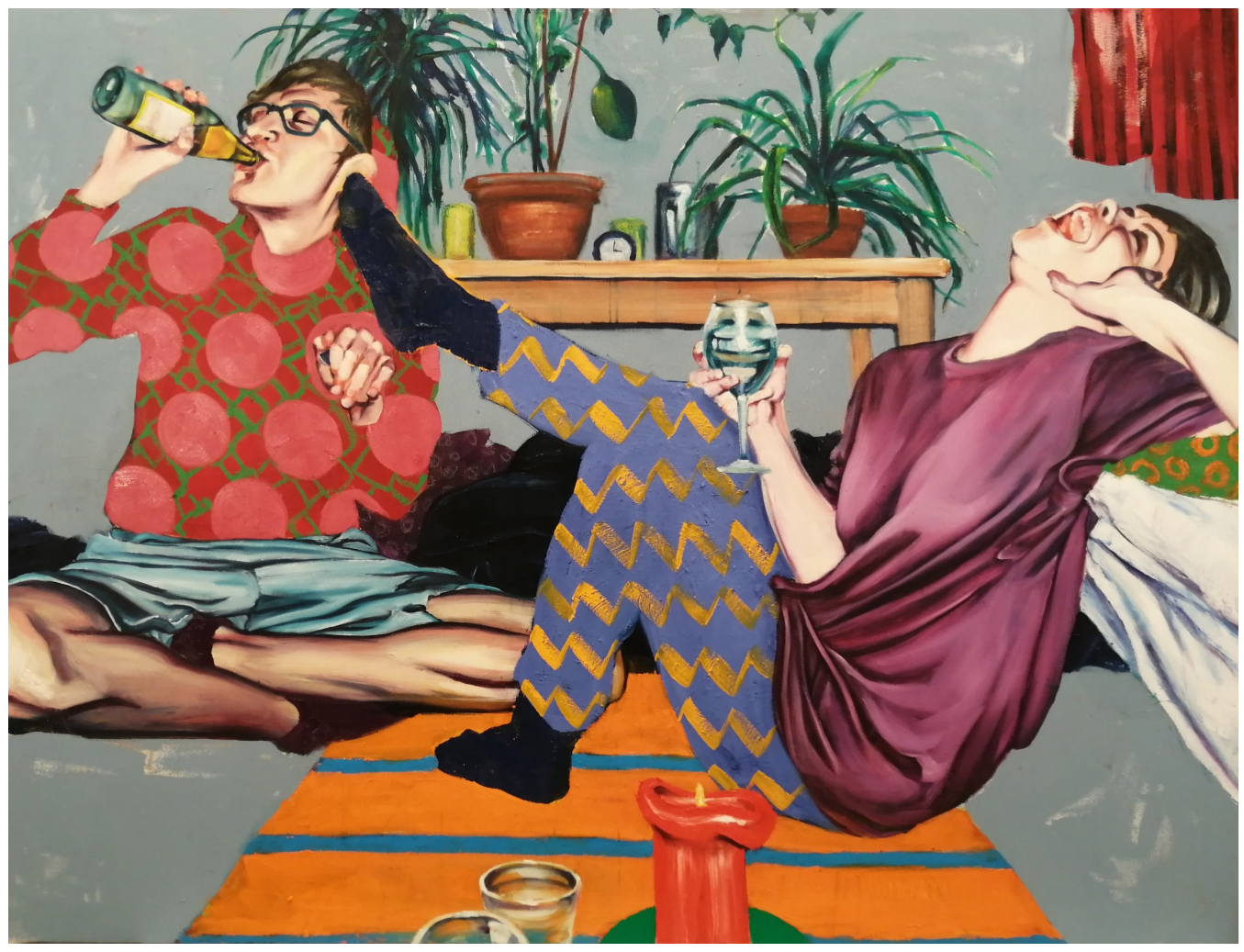

MAARIA JOKIMIES: SOKERIPALA PUOLIKS (2019) ÖLJY, ÖLJYPASTELLI JA AKRYYLI KANKAALLE $140 \times 180 \mathrm{CM}$ 


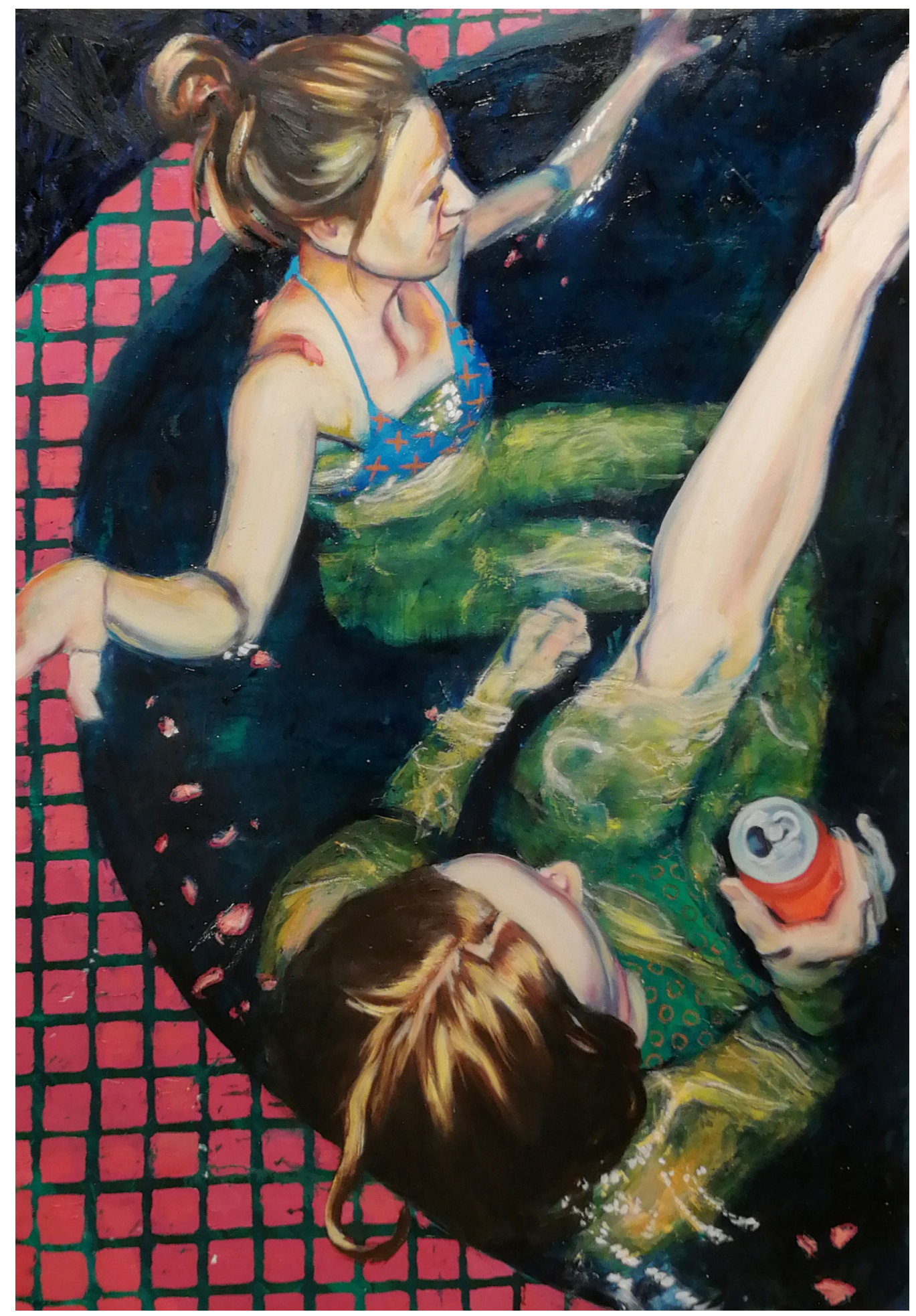

MAARIA JOKIMIES: AKVAARIOKUKKIA (2019) ÖLJY, ÖLJYPASTELLI JA AKRYYLI KANKAALLE 150 X 110 CM 


\section{MAARIA JOKIMIES}

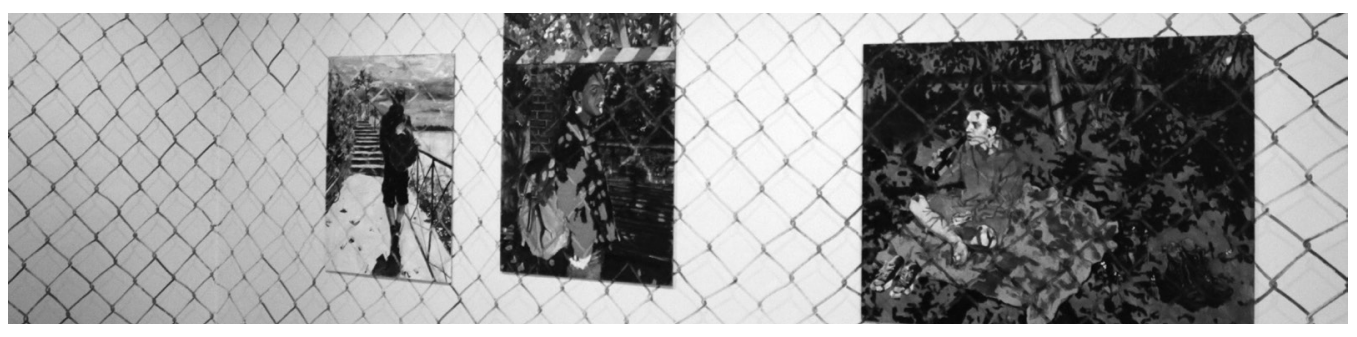

Maalaan figuratiivisia ja värikylläisiä öljyväriteoksia, joissa kuvaan sukupolveni nuorten juhlan ja yhteisöllisyyden hetkiä. Isompien öljyväriteosten rinnalla työstän myös pienïa maalauksia papereille. Maalausprosessissa yritän antaa tilaa materiaaleille ja oppia samalla tuntemaan ja hyödyntämään niiden erilaisia ominaisuuksia yhä paremmin. Työstän teoksia maalia lisäten ja välillä poistaen, antaen eri kerrosten ja vaiheiden näkyä. On loputtoman kiinnostavaa etsiä uusia tapoja levittää maalia ja tarkkailla sen muodostumista illuusioksi jostain olemassaolevasta.

Pyrin teoksissani tuomaan esille yksilön arkista tasapainoilua onnellisuuden kokemuksen ja lukemattomien erilaisten eettisyyteen, etuoikeuksiin sekä merkityksellisyyteen liittyvien kysymysten välillä. Tästä näkökulmasta maalaaminen itsessään on tavallaan ristiriitaista: miksi luoda tavaraa pullollaan olevaan maailmaan lisää taide-esineitä, joilla ei ole varsinaista käyttötarkoitusta. Koen kuitenkin, että tarvitsemme taidetta juuri tämän alati läsnäolevan eettisen kamppailun vastavoimaksi. Uskon maalauksen voimaan. Sen hitaasti aukeavat merkitykset voivat antaa katsojalleen fyysisen kokemuksen, mennä luihin ja ytimiin.

Muistelemisella ja muistojen kerrostumilla on vahva rooli teoksissani. Käytän lähtökohtana itse ottamiani valokuvia,joten maalauksissa esiintyvät henkilöhahmot ovat omaa lähipiiriäni. Haluan maalata sitä mitä näen ja näin antaa arvoa ympärilläni oleville henkilöille, esineille ja asioille, jotka ovat vuorovaikutuksessa kanssani. Näennäistä huolettomuutta huokuviin henkilökohtaisiin muistikuviini luon ristiriitaa yhdistämällä niihin toistoon perustuvia kuviointeja. Kuvion rooli vaihtelee maalauspinnan eri kohdissa - se esiintyy tilanteesta riippuen joko yleisperspektiivistä kuvattuna rakenteena, kuten aitana tai verkkona, tai esimerkiksi vaatteen kuosina. Saman maalauseleen kaavamaisessa toistossa on meditatiivisuutta mutta myös neuroottisuutta.

Rakastan maalaamista ja se on minulle elinehto. Maalatessani koen työskenteleväni ei-kielellisellä alueella, intiimissä vuorovaikutuksessa syntyvän teoksen kanssa. Ehkä tämän takia teosteni teemojen sanoittaminen ja niiden objektiivisempi tulkinta tapahtuu usein vasta prosessin loppuvaiheessa tai sen jälkeen. Tarkastellessani vanhempia maalauksiani koen ne jonkinlaisena eskapismina, paluuna hetkiin, jolloin minulla on ollut hyvä olla. Uudemmissa teoksissani ahdistavat asiat ovat vahvemmin näkyvillä.

Tulevia näyttelyitä vuonna 2021: Exhibition Laboratory (maaliskuu) ja Forsblomin Studio (lokakuu). 